\title{
Copper Deficiency as Cause of Unexplained Hematologic and Neurologic Deficits in Patient with Prior Gastrointestinal Surgery
}

\author{
Joanne Wu, MD, MPH, Mari Ricker, MD, and John Muench, MD, MPH
}

\begin{abstract}
Copper is a trace mineral essential to hematopoiesis and to the structure and function of the nervous system. Copper deficiency is a rare cause of anemia, leukopenia, and myeloneuropathy, but should be considered in the differential diagnosis in a patient with prior gastrointestinal surgery. We report the case of a 51-year-old woman admitted for nonspecific neurologic symptoms ultimately found to be due to copper malabsorption. (J Am Board Fam Med 2006;19:191-4.)
\end{abstract}

\section{Case Reports}

A 51-year-old female presented to the emergency department complaining of numbness and tingling in her distal lower extremities that had progressively worsened over the previous 4 weeks and had begun to affect her fingers 2 days before presentation. In addition, the patient stated that over the past 2 weeks she had experienced a progressively worsening shortness of breath, generalized weakness, fast heartbeat, and light-headedness.

She had undergone a gastrectomy 16 years ago with Roux-en-Y and partial small bowel resection for treatment of Zollinger-Ellison syndrome as well as a Whipple procedure for chronic pancreatitis. Since her surgeries, she received vitamin B12 supplementation intramuscularly and was converted to oral supplementation several months before her presentation in the emergency department.

On presentation, the patient's vital signs included a temperature of $36.7^{\circ} \mathrm{C}$, blood pressure of $121 / 84$, pulse of 80 , respiratory rate of 18 , oxygen saturation of $100 \%$ on room air, and weight of 43.2 $\mathrm{kg}$. Initial neurological evaluation revealed diminished sensitivity to light touch and vibration and decreased proprioception in her toes and ankles.

Submitted 24 March 2005; revised 2 August 2005; accepted 3 August 2005.

From the Oregon Health and Science University, Portland, OR.

Conflict of interest: none declared.

Corresponding author: Mari Ricker, MD, Oregon Health and Science University, 3181 SW Sam Jackson Park Road, Portland, OR 97239.
Her Babinski's reflex was positive bilaterally, and her Romberg was strongly positive. Her patellar and brachioradialis deep tendon reflexes were hyperreflexic bilaterally, but Achilles tendon reflexes were normal. Her cranial nerves were intact, and her sensation of pain and temperature were normal. Her motor strength was normal, but she had significant difficulty walking because of her sensory deficits. The physical examination was otherwise unremarkable.

Laboratory tests in the emergency department included a hematocrit of $17 \%$ (normal range, $33 \%$ to $44.6 \%$ ) with a mean corpuscular volume (MCV) of $105.9 \mathrm{fL}$ (normal range, 80 to $96 \mathrm{fL}$ ). At this point, the patient was admitted for management of anemia and further evaluation of neurologic symptoms. She received a transfusion of 2 units of packed red blood cells, which brought her hematocrit up to $27 \%$. She was also started on $100 \mathrm{mcg}$ of vitamin B12 intramuscularly daily and $1 \mathrm{mg}$ of folate orally daily.

The patient's neurological and laboratory findings were initially attributed to vitamin B12 or folate deficiency, given her history of gastrointestinal surgery and recent conversion to oral vitamin B12 supplementation. However, her vitamin B12 and folate levels were available by the third day of hospitalization, with a vitamin B12 level of 738 $\mathrm{pg} / \mathrm{mL}$ (normal range, 200 to $950 \mathrm{pg} / \mathrm{mL}$ ) and folate level greater than $24 \mathrm{ng} / \mathrm{mL}$ (normal level, $>0.9 \mathrm{ng} / \mathrm{mL}$ ). Methylmalonic acid was 0.77 $\mu \mathrm{mol} / \mathrm{L}$ (normal level, $<0.4 \mu \mathrm{mol} / \mathrm{L}$ ) and homocysteine was $4.7 \mu \mathrm{mol} / \mathrm{L}$ (normal range, 4 to 12 
$\mu \mathrm{mol} / \mathrm{L})$. Her reticulocyte count was elevated to $3.1 \%$ (normal range, $0.5 \%$ to $1.5 \%$ ), with an absolute count of $56,300 / \mathrm{mm}^{3}$ (normal range, 10,000 to $90,000 / \mathrm{mm}^{3}$ ). Serum iron, ferritin, and transferrin levels were normal, at $122 \mu \mathrm{g} / \mathrm{dL}$ (normal range, 40 to $150 \mu \mathrm{g} / \mathrm{dL}$ ), $259 \mathrm{ng} / \mathrm{mL}$ (normal range, 10 to $291 \mathrm{ng} / \mathrm{mL}$ ), and $220 \mathrm{mg} / \mathrm{dL}$ (normal range, 200 to $400 \mathrm{mg} / \mathrm{dL}$ ), respectively. Other laboratory findings included a white blood cell count of 2,000/ $\mathrm{mm}^{3}$ (normal range, 4400 to $11,000 / \mathrm{mm}^{3}$ ), with $40 \%$ neutrophils. However, she had normal platelet counts and prothrombin times. Peripheral blood smears showed nucleated red blood cells but no polymorphic nucleated neutrophils. A bone marrow biopsy was considered but refused by the patient. Serum lead level was normal. Serum and urine protein electrophoreses were normal. Cerebrospinal fluid studies showed no evidence of infection and no oligoclonal bands. An antinuclear antibody test was negative.

Imaging included magnetic resonance imaging (MRI) of the brain and cervical spine, which showed a possible abnormal signal in the posterior columns of the cervical spine. This was followed up with a high-resolution 3-Tesla MRI study for myelopathy, which was normal. Magnetic resonance angiography of the brain was then done with an incidental finding of frontal lobe developmental venous anomaly but was otherwise normal. A chest, abdominal, and pelvic computed tomography scan did not show any significant lymphadenopathy. After the third day of hospitalization, she developed additional neurologic symptoms including $4 / 5$ strength in her iliopsoas and hamstrings and $3 / 5$ dorsiflexion and plantar flexion of both ankles.

Further laboratory studies were done, and her ceruloplasmin level was found to be $<10 \mathrm{mg} / \mathrm{dL}$ (normal range, 20 to $60 \mathrm{mg} / \mathrm{dL}$ ), suggesting copper deficiency. The patient was started on $5.35 \mathrm{mg}$ of copper chloride intravenous supplementation daily (equivalent to $2 \mathrm{mg}$ of elemental copper). Her serum copper level was not checked until the third day of supplementation and was found to be low at $38 \mu \mathrm{g} / \mathrm{dL}$ (normal range, 80 to $155 \mu \mathrm{g} / \mathrm{dL}$ ). Her copper level increased to $53 \mu \mathrm{g} / \mathrm{dL}$ by the sixth day and to $72 \mu \mathrm{g} / \mathrm{dL}$ by the fourteenth day of treatment. Because high serum zinc levels have been associated with copper deficiency, the patient's serum zinc level was checked and found to be normal at $96 \mu \mathrm{g} / \mathrm{dL}$ (normal range, 65 to $256 \mu \mathrm{g} / \mathrm{dL}$ ).
The patient felt subjectively stronger by the fourteenth day after initiation of treatment, enabling her to ambulate more stably with a walker or cane, although her neurologic examination was objectively unchanged. She was then discharged from the hospital on continued daily intravenous infusions of copper chloride. Four months after discharge (at the time of this writing), she was still being treated with parenteral copper. Her copper level had normalized to $97 \mu \mathrm{g} / \mathrm{dL}$. Although her symptoms had not improved since going home, neither had they worsened.

\section{Discussion}

Copper deficiency is quite rare in humans because it is a nutrient that is readily consumed and has a very low daily requirement. ${ }^{1,2}$ It is present in legumes, meats, and nuts, and is absorbed through the mucosa of the stomach and proximal duodenum. With the plentiful supply of dietary copper, acquired copper deficiency is relatively uncommon compared with other causes of neurologic and hematologic deficits, so it can be easily missed when formulating differential diagnoses.

Copper is an essential trace metal that plays an integral role in many of our physiologic processes, including acting as a ligand to many proteins and enzymes. It is crucial in the structure of dopamine $\beta$-hydroxylase, the enzyme responsible for conversion of dopamine to norepinephrine, which mediates many neurologic functions. In addition, copper helps form cytochrome oxidase, a component in oxidative phosphorylation, and superoxide dismutase, an antioxidant. Copper also acts as a ligand to ferroxidase II, which oxidizes iron, allowing it to be mobilized and transported from hepatic stores to the bone marrow for use in erythropoiesis. ${ }^{2}$ Thus, copper deficiency results in excessive iron in the liver but insufficient iron in the marrow for effective erythropoiesis. ${ }^{3}$

Although rare, there are several potential causes of copper deficiency. In previous reports, copper deficiency has developed after gastric and bariatric surgery, probably due to malabsorption. ${ }^{4-6}$ Copper deficiency can also develop in patients receiving intravenous hyperalimentation without copper supplementation. ${ }^{7}$ It has also been found to be associated with hyperzincemia, ${ }^{8-10}$ although the causal relationship is still unclear. ${ }^{11}$ In addition, Menkes disease is a heritable disorder in which there is a 
failure to transport absorbed copper to the rest of the body from mucosal cells, which results in copper deficiency and its sequelae. ${ }^{12}$

Deficiency in the enzymes that copper normally supports can lead to striking neurologic deficits, including myelopathy, polyneuropathy, ataxia, optic neuritis, and demyelination. The first documented case of copper deficiency-associated myelopathy was of a 46-year-old woman who developed tetraparesis and painful paresthesias almost 20 years after gastrectomy. ${ }^{13}$ In another study of 13 patients with acquired copper deficiency, all had gait difficulty and lower limb paresthesias, with impaired proprioception and vibration sense in the distal lower limbs. ${ }^{5}$ Nine of those patients also had reduced perceptions of pinprick and touch in a stocking distribution, and 10 had positive Babinski's sign. Three of the 13 had increased T2 signal in the paramedian dorsal cervical cord.

Patients with copper deficiency can also develop profound hematopoietic deficits resulting in anemia and leukopenia, although not all patients with copper deficiency develop these manifestations. Sideroblastic changes and nuclear maturation defects causing anemia and neutropenia have been observed in erythroid precursors of patients with copper deficiency. ${ }^{1,14}$ A peripheral smear often reveals sideroblastic anemia with hypochromic microcytic red cells. Granulocyte levels can become very low, whereas platelet counts remain normal. In the study mentioned above in which 13 patients with copper deficiency were followed, 10 of the 13 had anemia or leukopenia. ${ }^{5}$ The MCV in anemia of copper deficiency is usually normal or increased, which can complicate the diagnosis, since megaloblastic anemia is also characteristic of vitamin B12 or folate deficiency.

Thus, the myelopathy, polyneuropathy, and anemia produced by copper deficiency can mimic the deficits seen with vitamin B12 or folate deficiency. Subacute combined degeneration from vitamin B12 deficiency involves the posterior and lateral columns of the spinal cord and sometimes the peripheral nerves. In previous reports of patients with B12 deficiency, symptoms at presentation included progressive sensory deficits, postural instability, paresthesias, and megaloblastic anemia. ${ }^{15,16}$ Likewise, a case report of a 38-year-old woman with folate deficiency describes a presentation with characteristics similar to ours, with pe- ripheral neuropathy, macrocytosis, and gait ataxia. ${ }^{17}$

The differential diagnosis of patients with presentations such as ours should include not only B12 and folate deficiency, but also problems such as central nervous system infection, multiple sclerosis, lupus, multiple myeloma, leukemia, or other malignancies. To diagnose copper deficiency, serum copper level should be measured; ceruloplasmin level is nonspecific and can be an acute phase reactant. Serum copper levels can be followed for adequacy of copper replacement therapy. Patients with copper deficiency have been successfully treated with oral copper in the past ${ }^{5}$ but not in the form of copper gluconate because of its poor bioavailability. ${ }^{18}$ Given that the cause of our patient's deficiency was her abnormal gastrointestinal anatomy, we opted to treat her with parenteral copper chloride.

In prior case studies, neurologic improvement has been quite variable, although most patients seem to retain some deficit even with treatment, and relapses can occur. 5,7,9,10,19,20 The hematologic deficits, however, generally correct within 2 months of beginning treatment. ${ }^{10,21}$

\section{Conclusion}

Our patient had a history of extensive gastrointestinal surgeries and recent development of waxing and waning hematologic and neurologic deficits. Her symptoms were ultimately attributed to copper deficiency. Prompt diagnosis and treatment of copper deficiency may help prevent the development of further neurologic deficits. Physicians should be aware that copper deficiency is part of the differential diagnosis in patients with unexplained neurologic symptoms, anemia, and leukopenia, especially those who have had prior gastrointestinal surgery.

\section{References}

1. Williams DM. Copper deficiency in humans. Semin Hematol 1983;20:118-28.

2. Turnlund J. Copper. In: Shils M, Olson J, Shike M, editors. Modern nutrition in health and disease. Philadelphia: Lippincott; 1998. p. 241.

3. Fields M, Bureau I, Lewis CG. Ferritin is not an indicator of available hepatic iron stores in anemia of copper deficiency in rats. Clin Chem 1997;43(8 Pt 1):1457-9.

4. Kumar N, Ahlskog JE, Gross JB, Jr. Acquired hypo- 
cupremia after gastric surgery. Clin Gastroenterol Hepatol 2004;2:1074-9.

5. Kumar N, Gross JB, Jr., Ahlskog JE. Copper deficiency myelopathy produces a clinical picture like subacute combined degeneration. Neurology 2004; 63:33-9.

6. Thaisetthawatkul P, Collazo-Clavell ML, Sarr MG, Norell JE, Dyck PJ. A controlled study of peripheral neuropathy after bariatric surgery. Neurology 2004; 63:1462-70.

7. Kumar N, Low PA. Myeloneuropathy and anemia due to copper malabsorption. J Neurol 2004;251: 747-9.

8. Hedera P, Fink JK, Bockenstedt PL, Brewer GJ. Myelopolyneuropathy and pancytopenia due to copper deficiency and high zinc levels of unknown origin: further support for existence of a new zinc overload syndrome. Arch Neurol 2003;60:1303-6.

9. Kumar N, Gross JB, Jr., Ahlskog JE. Myelopathy due to copper deficiency. Neurology 2003;61:273-4.

10. Prodan CI, Holland NR, Wisdom PJ, Burstein SA, Bottomley SS. CNS demyelination associated with copper deficiency and hyperzincemia. Neurology 2002;59:1453-6.

11. Kumar N, Ahlskog JE. Myelopolyneuropathy due to copper deficiency or zinc excess? Arch Neurol 2004; 61:604-5.

12. Menkes JH, Alter M, Steigleder GK, Weakley DR, Sung JH. A sex-linked recessive disorder with retardation of growth, peculiar hair, and focal cerebral and cerebellar degeneration. Pediatrics 1962; 29:764-79.
13. Schleper B, Stuerenburg HJ. Copper deficiency-associated myelopathy in a 46-year-old woman. J Neurol 2001;248:705-6.

14. Gregg XT, Reddy V, Prchal JT. Copper deficiency masquerading as myelodysplastic syndrome. Blood 2002;100:1493-5.

15. Jongen JC, Koehler PJ, Franke CL. [Subacute combined degeneration of the spinal cord: easy diagnosis, effective treatment]. Ned Tijdschr Geneeskd 2001; 145:1229-33.

16. Nogales-Gaete J, Jimenez P, Garcia P, et al. [Subacute combined degeneration of the spinal cord caused by vitamin B12 deficiency. Report of 11 cases]. Rev Med Chil 2004;132:1377-82.

17. Lopez-Hernandez N, Garcia-Escriva A, PampliegaPerez A, Alvarez-Sauco M, Martin-Estefania C, Asensio-Asensio M. [Peripheral and optical myeloneuropathy in a folic acid deficient alcoholic patient]. Rev Neurol 2003;37:726-9.

18. Pratt WB, Omdahl JL, Sorenson JR. Lack of effects of copper gluconate supplementation. Am J Clin Nutr 1985;42:681-2.

19. Kumar N, Crum B, Petersen RC, Vernino SA, Ahlskog JE. Copper deficiency myelopathy. Arch Neurol 2004;61:762-6.

20. Kumar N, McEvoy KM, Ahlskog JE. Myelopathy due to copper deficiency following gastrointestinal surgery. Arch Neurol 2003;60:1782-5.

21. Hayton BA, Broome HE, Lilenbaum RC. Copper deficiency-induced anemia and neutropenia secondary to intestinal malabsorption. Am J Hematol 1995; 48:45-7. 